\title{
Evaluation of Electromagnetic Absorption in Human Head from Mobile Phones
}

\author{
V.Bharat Kumar ${ }^{1}$, V.Gopi ${ }^{2}$, P.V.Y Jayasree ${ }^{3}$ \\ ${ }^{123}$ (ECE Department, GIT, GITAM University)
}

\begin{abstract}
Due to the rapid growth in the use of wireless communication systems, there has been a recent increase in public concern regarding the exposure of humans to Radio Frequency (RF) electromagnetic radiation. This is particularly evident in the case of mobile phone handsets. The scientists found some evidence of increase in glioma and acoustic neuroma brain cancer for mobile phone users. Mobile phone is operating at high frequencies to transmit and receive signals. With a distance of within $1 \mathrm{~cm}$ from a user's head, mobile phones can radiate radio frequency (RF) signals. Radiation from cell phone is defined by its Specific Absorption Rate (SAR) value. In India, SAR limit for cell phones is $1.6 \mathrm{~W} / \mathrm{Kg}$. which is actually for 6 minutes per day use. In this paper, we calculated transmitted power from mobile phone with spectrum analyzer and also evaluated absorption of Electromagnetic Radiation from Mobile Phones by outer layers (skin and bone) of human head.
\end{abstract}

Keywords: - Dielectric properties of human tissues, Radiation from Mobile, SAR, Shielding Effectiveness, Radiation Absorption

\section{INTRODUCTION}

Mobile phone technology has several advantages and has grown rapidly in the last decade. There are 6.8 billion mobile subscribers' worldwide, estimates the International Telecommunication Union (February, 2013) [1]. This is equivalent to 97 percent of the world population (7.1 billion according to ITU). China and India are major contributors of mobile population in the world. In china, there are nearly 1.2 billion mobile subscribers. In India, there are nearly 1.1 billion mobile subscribers (as per TRAI October, 2013 data) [2] means 90.4percent of total population in India.

Due to this rapid growth in the use of mobile phones, in public concern regarding the exposure of Radio Frequency (RF) electromagnetic radiation onto the human head is unsafe. It is broadly accepted that mobile phones cause heating of the human organ exposed to their radiation and specifically the human head. Therefore, many countries have provided various guidelines and standards that specify safety levels for such exposure to RF radiation. The National Radiological Protection Board (NRPB) in UK and the International Commission on Non-Ionizing Radiation Protection (ICNIRP) [3] in Europe has also published guidelines which generally follow published standards such as Institute of Electrical and Electronics Engineers (IEEE) [4].

The SAR limit of the European Standard will he used as a safety guideline for mobile phones. The European standards for testing mobile phones, EN50360: 2001 and EN50361: 2001 were published in July 2001. They specify the compliance of mobile phones. With the basic restrictions and the measurement methods of SAR related to human exposure to electromagnetic fields in the range $300 \mathrm{MHz}$ to $3 \mathrm{GHz}$. The Specific Absorption Rate (SAR), used in the assessment of mobile phone handsets, is a measure of the amount of electromagnetic energy absorbed by biological tissue, particularly in the human body. For example, the SAR limit specified in IEEE C95.1: 1999 is $1.6 \mathrm{~W} / \mathrm{kg}$ in a $1 \mathrm{~g}$ averaging mass while that specified in ICNIRP guidelines is $2 \mathrm{~W} / \mathrm{kg}$ in a $10 \mathrm{~g}$ averaging mass. This means that actually for 6 minutes per day use. It has a safety margin of 3 to 4 , so a person should not use cell phone for more than 18 to 24 minutes per day.

Majority of the people have reported that if they use cell phones for more than 20 minutes, their ear lobes get warm, which is due to heating of blood by microwave energy of cell phones. The problem starts with a pain in the ear that gradually develops into tinnitus or a ringing sensation which finally leads to hearing loss and ear tumor. Also, overuse of cell phones leads to drying of the skin and fluid in the eyes, sleep disorder, lack of concentration, memory loss, and even cancer.

The induced SAR of an RF transmitting device is obtained by measuring the electric field in simulated human tissue in close proximity to the device, and is calculated by the formula

$\operatorname{SAR}=\frac{\sigma \mathrm{E}_{\mathrm{i}}^{2}}{\rho}$

Where $E_{\mathrm{i}}$ : rms value of the electric field strength in the tissue $\mathrm{V} / \mathrm{m}$;

$\sigma$ : conductivity of body tissue in $\mathrm{S} / \mathrm{m}$;

$\rho$ : density of body tissue in $\mathrm{kg} / \mathrm{m}^{3}$. 
Table1: Mobile operating frequencies

\begin{tabular}{|l|l|l|l|l|}
\hline Network & \multicolumn{2}{|l|}{ Uplink Frequencies } & \multicolumn{2}{l|}{ Downlink Frequencies } \\
\hline CDMA & 824 & 849 & 869 & 894 \\
\hline GSM900 & 890 & 915 & 935 & 960 \\
\hline GSM1800 & 1710 & 1785 & 1805 & 1880 \\
\hline 3G & 1920 & 1980 & 2110 & 2170 \\
\hline
\end{tabular}

In India, there are 2G main types of cellular phone system: CDMA, GSM900, GSM1800, 3G. These operating frequencies are as shown in table 1 . When a human body is exposed to the electromagnetic radiation, it absorbs radiation, because human body consists of $70 \%$ liquid. It is similar to that of cooking in the microwave oven where the water in the food content is heated first. Microwave absorption effect is much more significant by the body parts, which contain more fluid (water, blood, etc.), like the brain which consists of about $90 \%$ water. Effect is more pronounced where the movement of the fluid is less, for example, eyes, brain, joints, heart, abdomen, etc. Also, human height is much greater than the wavelength of the cell tower transmitting frequencies, so there are multiple resonances in the body, which creates localized heating inside the body. This results in boils, drying up of the fluids around eyes, brain, joints, heart, abdomen, etc.

Products are available for SAR reductions which add external shields to mobile phones, particularly near the ear-piece of the handsets. Materials, such as conductive mesh, conductive fabric, and conductive foam are now available and have been displayed in recent EMC exhibitions. These materials could also be applied to reduce the SAR of mobile phone handsets. Over the years, lots of attentions have been paid to the analysis of SAR in human head due to the complexity and large scale involved in this kind of problems [5-10]. Recently, research efforts have been devoted to the reduction of peak SAR in human head for handset applications.

\section{MEASUREMENT OF RADIATION FROM MOBILES}

1. In this paper, we are calculating the transmitted powers of different mobiles with different operators using spectrum analyzer kit [11]. The tools we used to know the Transmitted power from mobile are spectrum analyzer, preamplifier, ANT-01 Probe and BNC Cable.

2. The Fig 1 shows the Main tool of EMI diagnostic package and Fig 2 shows the spectrum Analyzer. The Connections of Spectrum Analyzer with different EMI probes used to measure radiated electric and magnetic fields from mobile phones is shown in fig. 3.

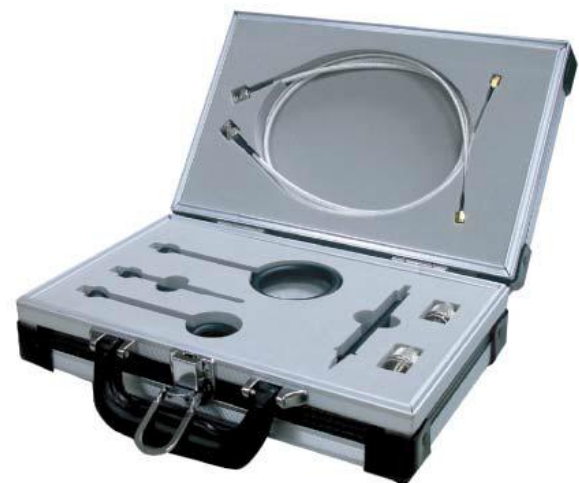

Fig.1 The main tool of EMI diagnostic package

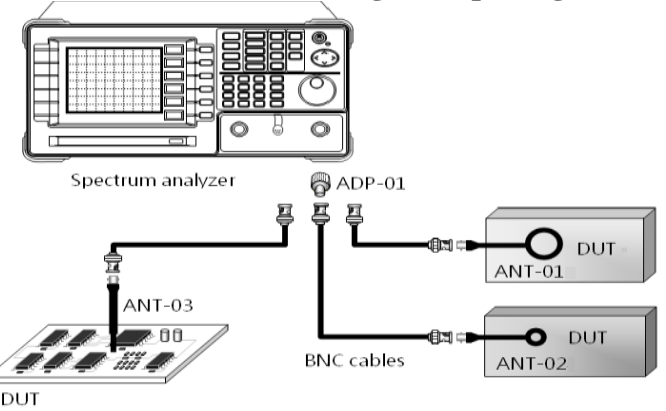

Fig.3 BNC probe Connections is well-posed with $\mathbf{R F}$ cable and loop probes ANT-01, ANT-02 and ANT-03

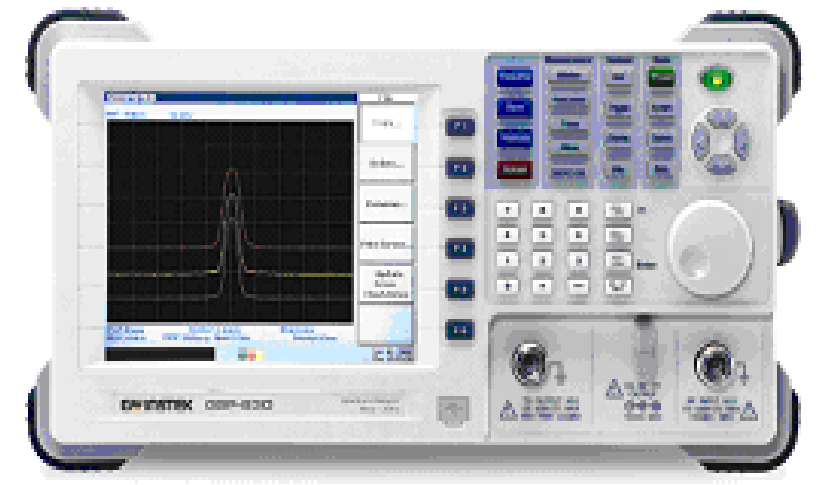

Fig. 2 The typical 3GHz Spectrum Analyzer 
3. The radiated powers of different mobiles are measured using above equipment when mobile is in active state (Outgoing call or Incoming call).

4. The readings are taken from spectrum analyzer of different mobiles with different operators as listed in Table 2. In Table 2, ' $\mathrm{Tx}$ ' is related to when mobile is in dialing Mode and ' $\mathrm{Rx}$ ' is related to When mobile is in receiving mode.

Table 2: The Readings of Spectrum Analyzer

\begin{tabular}{|l|l|l|l|l|l|}
\hline $\begin{array}{l}\text { S.N } \\
\mathbf{o}\end{array}$ & OPERATOR & $\begin{array}{l}\text { FREQUENC } \\
\text { Y }(\mathbf{M H z})\end{array}$ & MOBILE & $\begin{array}{l}\text { Tx/ } \\
\mathbf{R x}\end{array}$ & $\begin{array}{l}\text { POWER } \\
(\mathbf{d B m})\end{array}$ \\
\hline 1 & AIRTEL & 894 & SAMSUNG-GTE3213K & $\mathrm{Tx}$ & -39.7 \\
\hline 2 & AIRTEL & 894 & SAMSUNG-GTE3213K & $\mathrm{Rx}$ & -33.7 \\
\hline 3 & BSNL & 906 & SAMSUNG-GTS5360 & $\mathrm{Tx}$ & -36.6 \\
\hline 4 & BSNL & 906 & SAMSUNG-GTS5360 & $\mathrm{Rx}$ & -32.6 \\
\hline 5 & VODAFONE & 1782 & NOKIA-X3 & $\mathrm{Tx}$ & -34.5 \\
\hline 6 & AIRTEL & 894 & SONY-XPERIA & $\mathrm{Tx}$ & -44.7 \\
\hline 7 & AIRTEL & 894 & SONY-XPERIA & $\mathrm{Rx}$ & -44.3 \\
\hline 8 & AIRTEL & 905 & SAMSUNG-GTE3213K & $\mathrm{Rx}$ & -21.8 \\
\hline 9 & AIRTEL & 898.6 & SAMSUNG-GTE3213K & $\mathrm{Tx}$ & -25.6 \\
\hline 10 & VODAFONE & 1780 & NOKIA-1600 & $\mathrm{Rx}$ & -29.5 \\
\hline 11 & VODAFONE & 1782 & NOKIA-1600 & $\mathrm{Tx}$ & -29.9 \\
\hline 12 & BSNL & 916 & SAMSUNG-GTS5360 & $\mathrm{Rx}$ & -22.4 \\
\hline 13 & BSNL & 902 & SAMSUNG-GTS5360 & $\mathrm{Tx}$ & -25 \\
\hline 14 & VODAFONE & 1779.2 & SAMSUNG-GTE3213K & $\mathrm{Rx}$ & -20.2 \\
\hline 15 & VODAFONE & 1782.6 & SAMSUNG-GTE3213K & $\mathrm{Tx}$ & -26.2 \\
\hline 16 & AIRTEL & 902 & NOKIA-1600 & $\mathrm{Rx}$ & -24.4 \\
\hline 17 & AIRTEL & 905 & NOKIA-1600 & $\mathrm{Tx}$ & -12.2 \\
\hline 18 & AIRTEL & 905.4 & SAMSUNG-GALAXY GRAND & $\mathrm{Rx}$ & -25.8 \\
\hline 19 & AIRTEL & 902 & SAMSUNG-GALAXY GRAND & $\mathrm{Tx}$ & -20 \\
\hline
\end{tabular}

\section{MEASUREMENT OF ABSORPTION POWER OF HUMAN HEAD}

The Absorption power of human head to be calculated by calculating the shielding effectiveness of the human head. For this calculation, we consider human head as a two layer laminated shield as shown in figure 5. Here we assume skin and bone are two layers and have thickness of $0.5 \mathrm{~cm}$.

Table 3: Dielectric Properties of Human Tissues, R.P= Relative permittivity

\begin{tabular}{|c|c|c|c|c|c|c|c|}
\hline \multirow[b]{2}{*}{ S.No } & \multirow[b]{2}{*}{$\begin{array}{l}\text { Frequency } \\
{[\mathrm{MHz}]}\end{array}$} & \multicolumn{2}{|l|}{ Skin Dry } & \multicolumn{2}{|l|}{ Bone Cortical } & \multicolumn{2}{|c|}{ Brain White Matter } \\
\hline & & $\begin{array}{l}\text { Conductivity } \\
(\sigma)[\mathrm{S} / \mathrm{m}]\end{array}$ & $\begin{array}{l}\text { R.P } \\
(\varepsilon)\end{array}$ & $\begin{array}{l}\text { Conductivity } \\
(\sigma)[\mathbf{S} / \mathbf{m}]\end{array}$ & $\begin{array}{l}\text { R.P } \\
\text { (घ) }\end{array}$ & $\begin{array}{l}\text { Conductivity } \\
(\sigma)[\mathbf{S} / \mathbf{m}]\end{array}$ & $\begin{array}{l}\text { R.P } \\
(\varepsilon)\end{array}$ \\
\hline 1. & 800 & 0.83361 & 41.978 & 0.13161 & 12.552 & 0.56067 & 39.251 \\
\hline 2. & 850 & 0.85021 & 41.676 & 0.13738 & 12.502 & 0.57562 & 39.06 \\
\hline 3. & 900 & 0.86674 & 41.405 & 0.14331 & 12.454 & 0.59079 & 38.886 \\
\hline 4. & 950 & 0.88325 & 41.16 & 0.14941 & 12.408 & 0.60622 & 38.726 \\
\hline 5. & 1000 & 0.89977 & 40.936 & 0.15566 & 12.363 & 0.6219 & 38.577 \\
\hline 6. & 1050 & 0.91635 & 40.731 & 0.16207 & 12.321 & 0.63787 & 38.439 \\
\hline 7. & 1100 & 0.933 & 40.543 & 0.16863 & 12.279 & 0.65412 & 38.309 \\
\hline 8. & 1150 & 0.94976 & 40.369 & 0.17535 & 12.239 & 0.67066 & 38.187 \\
\hline 9. & 1200 & 0.96665 & 40.208 & 0.18221 & 12.2 & 0.68751 & 38.072 \\
\hline 10. & 1250 & 0.98369 & 40.057 & 0.18922 & 12.162 & 0.70468 & 37.963 \\
\hline 11. & 1300 & 1.0009 & 39.917 & 0.19638 & 12.124 & 0.72215 & 37.859 \\
\hline 12. & 1350 & 1.0183 & 39.785 & 0.20368 & 12.087 & 0.73995 & 37.76 \\
\hline 13. & 1400 & 1.0359 & 39.661 & 0.21111 & 12.051 & 0.75807 & 37.665 \\
\hline 14. & 1450 & 1.0536 & 39.544 & 0.21868 & 12.016 & 0.77652 & 37.573 \\
\hline 15. & 1500 & 1.0716 & 39.433 & 0.22638 & 11.981 & 0.7953 & 37.485 \\
\hline 16. & 1550 & 1.0899 & 39.328 & 0.23421 & 11.947 & 0.81441 & 37.4 \\
\hline 17. & 1600 & 1.1083 & 39.228 & 0.24217 & 11.913 & 0.83385 & 37.318 \\
\hline 18. & 1650 & 1.127 & 39.133 & 0.25025 & 11.879 & 0.85362 & 37.238 \\
\hline 19. & 1700 & 1.146 & 39.042 & 0.25846 & 11.846 & 0.87373 & 37.16 \\
\hline
\end{tabular}




\begin{tabular}{|l|l|l|l|l|l|l|l|}
\hline 20. & 1750 & 1.1652 & 38.955 & 0.26678 & 11.813 & 0.89417 & 37.085 \\
\hline 21. & 1800 & 1.1847 & 38.872 & 0.27522 & 11.781 & 0.91494 & 37.011 \\
\hline 22. & 1850 & 1.2045 & 38.792 & 0.28377 & 11.748 & 0.93605 & 36.939 \\
\hline 23. & 1900 & 1.2245 & 38.714 & 0.29243 & 11.716 & 0.95748 & 36.868 \\
\hline 24. & 1950 & 1.2448 & 38.64 & 0.3012 & 11.685 & 0.97926 & 36.799 \\
\hline 25. & 2000 & 1.2654 & 38.568 & 0.31007 & 11.654 & 1.0014 & 36.732 \\
\hline
\end{tabular}

To calculate the intrinsic impedance $(\eta)$, Propagation constant $(\gamma)$, Wave impedance in electric field $\left(\mathrm{Z}_{\mathrm{E}}\right)$, absorbed power $(\mathrm{A})$, dielectric properties of skin, bone and Brain white matter are needed. From reference [12], we got the dielectric values like Permittivity $\left(\varepsilon_{\mathrm{r}}\right)$, Conductivity $(\sigma)$ and Permeability $(\mu)$ of skin, bone and brain white matter are shown in Table 3. These dielectric values are varying according to the frequency of operation of mobiles but mass density $(\rho)$ is not varying. Using of these values and shielding equations [13] as mentioned below we calculated the absorbing power of skin at different frequencies of mobile operation.

$\eta=\sqrt{\frac{\mathrm{jw \mu}}{\sigma}}=(1+\mathrm{j}) \sqrt{\frac{\pi \mu \mathrm{f}}{\sigma}}=\sqrt{\frac{2 \pi * 4 \pi * 10^{-7} * \mathrm{f}}{\sigma}}=2 \pi * \sqrt{\frac{\mathrm{f}}{5 \sigma}}$ (' $\mathrm{f}$ ' is in MHz)

$\gamma=\sqrt{\mathrm{jw \mu \sigma}}=(1+\mathrm{j}) \sqrt{\pi \mu \mathrm{f} \sigma}=\sqrt{2 \pi * 4 \pi * 10^{-7} * \mathrm{f} * \sigma}=2 \pi \sqrt{0.2 \mathrm{f} \sigma}$

$\mathrm{Z}_{\mathrm{E}}=\frac{\eta_{0} \lambda_{0}}{2 \pi \mathrm{r}}=\frac{\eta_{0} \mathrm{c}}{2 \pi \mathrm{fr}}=\frac{1800000}{\mathrm{f}(\mathrm{MHz})}=\mathrm{Z}_{\mathrm{W}}$ (' $\mathrm{r}$ ' is distance between mobile and ear, i.e $1 \mathrm{~cm}$ )

In equation 4, ' $r$ ' is the distance from mobile to skin considers it as $1 \mathrm{~cm}$, ' $\eta_{0}$ ' free space intrinsic impedance is $120 \pi$, 'c' is light velocity $3 * 10^{8} \mathrm{~m} / \mathrm{s}$.

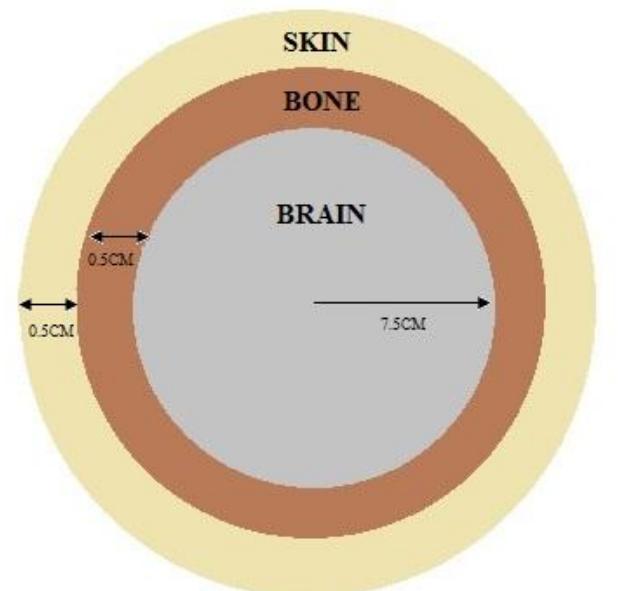

Fig.4 Human head model for SAR calculation.

From the shielding concept we got equations for two layer laminated shield. The total transmission coefficient of radiated wave in human skin and bone is given by [14-16]

$\mathrm{T}=\mathrm{p}\left[\left(1-\mathrm{q}_{1} \mathrm{e}^{-2 \gamma_{\mathrm{s}} \mathrm{l}_{1}}\right)\left(1-\mathrm{q}_{2} \mathrm{e}^{-2 \gamma_{\mathrm{b}} \mathrm{l}_{2}}\right)\right]^{-1} \mathrm{e}^{-\gamma_{\mathrm{s}} \mathrm{l}_{1}-\gamma_{\mathrm{b}} \mathrm{l}_{2}}$

and here,

$P=\frac{8 Z_{w} \eta_{s} \eta_{b}}{\left(Z_{w}+\eta_{s}\right)\left(\eta_{s}+\eta_{b}\right)\left(\eta_{b}+\eta_{f}\right)}$

$\mathrm{q}_{1}=\frac{\left(\eta_{\mathrm{s}}-\mathrm{Z}_{\mathrm{w}}\right)\left[\eta_{\mathrm{s}}-\mathrm{Z}\left(\mathrm{l}_{1}\right)\right]}{\left(\eta_{\mathrm{s}}+\mathrm{Z}_{\mathrm{w}}\right)\left[\eta_{\mathrm{s}}+\mathrm{Z}\left(\mathrm{l}_{1}\right)\right]}$

$\mathrm{q}_{2}=\frac{\left(\eta_{\mathrm{b}}-\eta_{\mathrm{s}}\right)\left[\eta_{\mathrm{b}}-\eta_{\mathrm{f}}\right]}{\left(\eta_{\mathrm{b}}+\eta_{\mathrm{s}}\right)\left[\eta_{\mathrm{b}}+\eta_{\mathrm{f}}\right]}$

$\mathrm{Z}\left(\mathrm{l}_{1}\right)=\eta_{\mathrm{b}} \frac{\left(\eta_{\mathrm{f}} \cosh \gamma_{\mathrm{b}} \mathrm{l}_{2}+\eta_{\mathrm{b}} \sinh \gamma_{\mathrm{b}} \mathrm{l}_{2}\right)}{\left(\eta_{\mathrm{b}} \cosh \gamma_{\mathrm{b}} \mathrm{l}_{2}+\eta_{\mathrm{f}} \sinh \gamma_{\mathrm{b}} \mathrm{l}_{2}\right)}$

$\eta_{\mathrm{s}}, \eta_{\mathrm{b}}, \eta_{\mathrm{f}}$ are Characteristic impedances of skin, bone and flesh respectively.

$\gamma_{\mathrm{s}}, \gamma_{\mathrm{b}}, \gamma_{\mathrm{f}}$ are propagation constants of wave in skin, bone and flesh of human body respectively.

$l_{1}, l_{2}$ are thickness of skin and bone i.e equal to $0.5 \mathrm{~cm}$.

$\mathrm{Z}_{\mathrm{w}}$ is wave impedance, we can calculate it from equation 4 .

and the shielding effectiveness is expressed as

$\mathrm{S}=-20 \log _{10}|\mathrm{~T}|=\mathrm{A}+\mathrm{R}+\mathrm{B}$ 
The absorption loss of the laminated shield (skin and bone) is simply the sum of those for the two layers of the shield and is given by

$\mathrm{A}=20 \log _{10} \mid \mathrm{e}^{\gamma_{\mathrm{s}} \mathrm{l}_{1}+\gamma_{\mathrm{b}} \mathrm{l}_{2} \mid}$

The corresponding reflection loss is

$\mathrm{R}=-20 \log _{10}|\mathrm{P}|$

The sum of the reflection losses at each interface. The correction term due to successive re-reflection is

$B=20 \log _{10}\left|1-\mathrm{q}_{1} \mathrm{e}^{-2 \gamma_{\mathrm{s}} \mathrm{l}_{1}}\right|+20 \log _{10}\left|1-\mathrm{q}_{2} \mathrm{e}^{-2 \gamma_{\mathrm{b}} \mathrm{l}_{2}}\right|$

This is not simply the sum of correction factors for the individual lamina since $q_{1}$ and $q_{2}$ involves the impedance looking into the second sheet.

\section{RESULTS}

With the use of MATLAB software, if we plot the equations with respect to frequency resultant graphs are obtained as shown in below figures. From the Fig.5,it is observed that the shielding effectiveness of two layers i.e. skin and bone of human head incresed with the increase in operating frequency of mobile. It is obtained that from Fig.6, the absorbed power increases with increase in frequency and it will be a problem to skin and bone. From Fig.7, we have observd that the reflected power of two layers skin and bone of human head is decreases whenever frequency of operation increased. The reflected power varies from $-53.6 \mathrm{~dB}$ to $-54.5 \mathrm{~dB}$. The comparision of shielding effectiveness, Absorbed power and Reflected power with respect to frequency is represented in Fig. 8.

With this analysis, we evaluated the power absorbed by skin and bone structure of our head and from this we estimate how much power can be entered into the flesh of human brain.

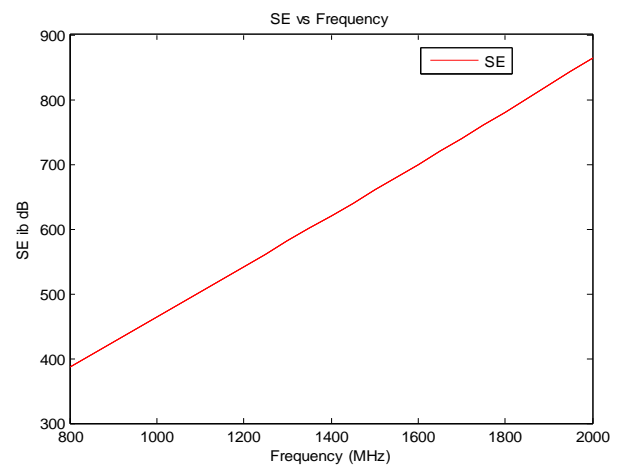

Fig.5 Variation of SE at two layers of skin and bone against frequency

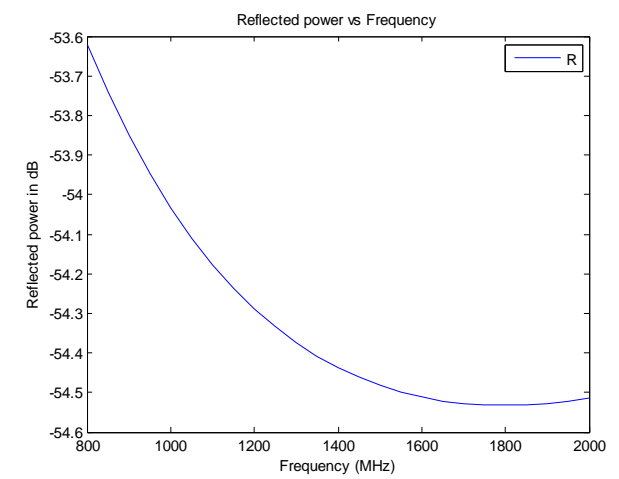

Fig.7 Variation of Reflected power at two layers of skin and bone against frequency

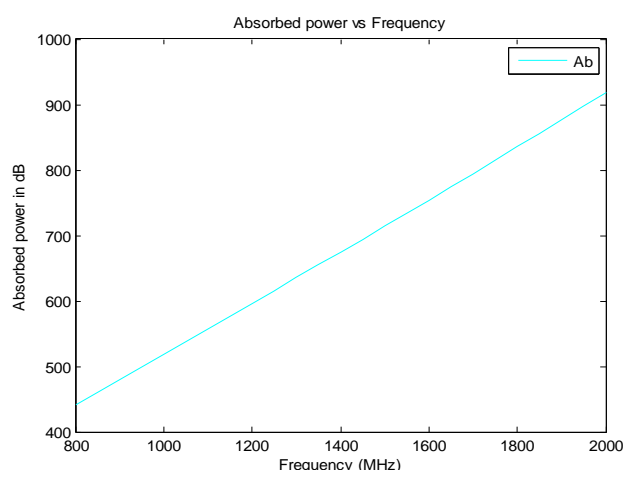

Fig.6 Variation of Absorbed power at two layers of skin and bone against frequency

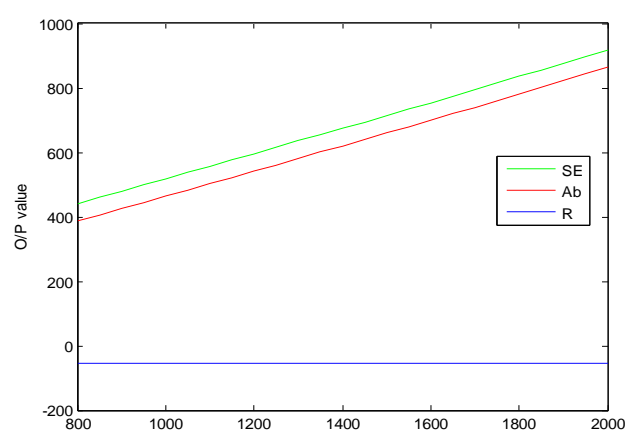

Fig. 8 Variation of SE, Absorption loss and reflection loss at two layers skin and bone against frequency

\section{CONCLUSION}

In this paper, we have calculated how much power is transmitted from various mobiles which are operated at different frequencies. Then we calculated how much power is absorbed, reflected by skin and bone using shielding technology when we are using mobile phones. Since the cells of skin will be dry, this absorbed power will cause skin diseases. 
From these results, we can conclude that $3 \mathrm{G}$ mobiles produce more radiation as compared to $2 \mathrm{G}$ mobiles. Based on this analysis, the radiation intensity levels on human head will be reduced to the permissible levels. This method will lead to select suitable shield material for mobile frequency range.

\section{ACKNOWLEDGEMENTS}

We thank the management of GITAM University for all the support and encouragement rendered in this project. We also extend our thanks to the Vice Chancellor and Registrar of GITAM University and the Principal of GITAM Institute of Technology for providing the required facilities for carrying out this work.

\section{REFERENCES}

[1] Web link is http://mobithinking.com/mobile-marketing-tools/latest-mobilestats/a\# subscribers.

[2] Web link http://www.trai.gov.in/WriteReadData/PressRealease/ Document/PR-TSD-Sep,\%2013.pdf

[3] ICNIRP, "Guidelines for limiting exposure to time-varying electric, magnetic, and electromagnetic fields (up to $300 \mathrm{GHz}$ )," Health Phys., Vol. 74, 494-522, 1998.

[4] "IEEE standard for safety levels with respect to human exposure to radio frequency electromagnetic fields $3 \mathrm{kHz}$ to $300 \mathrm{GHz}$ " IEEE Std. C95.1, 2005.

[5] Khalatbari, S., D. Sardari, A. A. Mirzaee, and H. A. Sadafi, "Calculating SAR in two models of the human head exposed to mobile phones radiations at 900 and $1800 \mathrm{MHz}$," PIERS Online, Vol. 2, No. 1, 104-109, 2006.

[6] Hirata, A.K. Shirai, and O. Fujiwara, "On averaging mass of SAR correlating with temperature elevation due to a dipole antenna," Progress In Electromagnetics Research, PIER 84, 221-237, 2008.

[7] Mahmoud, K. R., M. El-Adawy, S. M. M. Ibrahem, R. Bansal, and S. H. Zainud-Deen, "Investigating the interaction between a human head and a smart handset for $4 \mathrm{~g}$ mobile communication systems, " Progress In Electromagnetics Research C, Vol. 2, 169-188, 2008.

[8] Kouveliotis, N. K. and C. N. Capsalis, "Prediction of the SAR level induced in a dielectric sphere by a thin wire dipole antenna," Progress In Electromagnetics Research, PIER 80, 331-336, 2008.

[9] Ebrahimi-Ganjeh, M. A. and A. R. Attari, "Interaction of dual band helical and pifa handset antennas with human head and hand," Progress In Electromagnetics Research, PIER 77, 225-242, 2007.

[10] Kuo, L.-C., Y.-C. Kan, and H.-R. Chuang, "Analysis of a 900/1800-MHz dual-band gap loop antenna on a handset with proximate head and hand model," Journal of Electromagnetic Waves and Applications, Vol. 21, No. 1, 107-122, 2007.

[11] "The optimal solution to ensure the excellent certification quality of EMI testing" application note of Good will instrument co. ltd.

[12] Web link http://niremf.ifac.cnr.it/tissprop/htmlclie/htmlclie.htm\#stsftag

[13] Richard B. Schulz, V.C Plantz, and D.R Brush "Shielding Theory and Practice" IEEE transactions on electromagnetic compatibility, vol. 30, no. 3, August 1988.

[14] PVY Jayasree "Shielding Effectiveness of Laminated Shields", Journal of Radio Engineering, Vol.17, No. 4, pp. 34- 37, December, 2008

[15] PVY Jayasree "Shielding Effectiveness of Single shields of conductive polymers - A case study" Springer Journal of The Institution of Engineers (India): Series B, Vol.90, pp. 26- 29, July 2009.

[16] PVY Jayasree "Analysis of Shielding Effectiveness of Single, Double And Laminated Shields for Oblique Incidence of EM Waves” Progress In Electromagnetics Research B (PIER B) Vol. 22, 187-202, 2010. 